\title{
Socio-demographic Characteristics of Vesico-vaginal fistula (VVF) patients attended at a tertiary Care Hospital in Bangladesh
}

\author{
Shimul Akter ${ }^{1}$, Naznin Rashid Shewly², Kashefa Khatun ${ }^{3}$, Rokshana Parvin Nupur', \\ Kamrun Nahar ${ }^{5}$, Nilufar Sultana ${ }^{6}$, Farzana Sharmin ${ }^{7}$
}

\begin{abstract}
${ }^{1}$ Assistant Professor, Department of Gynaecology and Obstetrics, Monowara Sikder Medical College, Shariatpur, Bangladesh; ${ }^{2}$ Associate Professor, Department of Gynaecology \& Obstetrics, Shaheed Suhrawardy Medical College, Dhaka, Bangladesh; ${ }^{3}$ Associate Professor, Department of Gynaecology \& Obstetrics, Dhaka Medical College, Dhaka, Bangladesh; ${ }^{4}$ Registrar, Department of Gynaecology and Obstetrics, Enam Medical College, Savar, Dhaka, Bangladesh; ${ }^{5}$ Junior Consultant (Gynaecology and Obstetrics), President's Office, Bangabhaban, Dhaka, Bangladesh; ${ }^{6}$ Professor, Department of Gynaecology and Obstetrics, Dhaka Medical College, Dhaka, Bangladesh; ${ }^{7}$ Assistant Professor, Department of Gynaecology \& Obstetrics, Bangabandhu Sheikh Mujib Medical University, Dhaka, Bangladesh
\end{abstract}

[Received: 12 April 2020; Accepted: 20 May 2020; Published: 1 July 2020]

\begin{abstract}
Background: Vesico-vaginal fistula can occur in different women with varied socio-economic condition. Objectives: The purpose of the present study was to see the socio-demographic characteristics of vesico-vaginal fistula (VVF) patients attended at a tertiary care hospital in Bangladesh. Methodology: This cross-sectional study was carried out from July 2013 to December 2013 for a period of 6 months in the National Fistula Centre in the Department of Obstetrics \& Gynaecology at Dhaka Medical College Hospital $(\mathrm{DMCH})$, Dhaka, Bangladesh. All patients who underwent surgical repair for iatrogenic VVF in National Fistula Centre of the department of Obstetrics and Gynaecology of Dhaka Medical College Hospital were included in this study. Patients who got themselves admitted to Obstetrics \& Gynaecology department of $\mathrm{DMCH}$ with the complaints of fistula. The entire selected patients were interviewed for detailed socio-demographic characteristics. Result: A total number of 51 cases of VVF were recruited for this study. The mean age was $46.02( \pm$ SD 6.104$)$ years. Most of the respondents were illiterate $(55.0 \%)$ and one-third patients had primary level education. The number of highly educated patients was scarce $(12.0 \%)$. It was evident that average age at marriage of the patients was $15.8( \pm 4.74)$ years. Some females were forced to accept marriage at the age of 10 years. The mean interval between initiation of menstruation and the marriage was only 4.72 years. Mothers were on an average 17.48 years old at the time of first delivery. Conclusion: In conclusion middle age illiterate women are most commonly suffering from VVF. [Journal of National Institute of Neurosciences Bangladesh, July 2020;6(2): 114-117]
\end{abstract}

Keywords: Socio-demographic Characteristics; Vesico-vaginal fistula; VVF

Correspondence: Dr. Shimul Akter, Assistant Professor, Department of Gynaecology and Obstetrics, Monowara Sikder Medical College, Bhedorgonj, Shariatpur, Bangladesh; Email: shimulakter1072@gmail.com; Cell no.: +8801927643367

Conflict of interest: There is no financial conflict of interest relevant to this paper to disclose.

Funding agency: This research project was not funded by any group or any institution.

Contribution to authors: Akter S, Shewly NR, Sultana N, Khatun K contributed from the protocol preparation, data collection up to report writing. Manuscript writing was performed by Akter S, Shewly NR; Nupur RP, Nahar K, Sharmin F have revised the manuscript.

How to cite this article: Akter S, Shewly NR, Khatun K, Nupur RP, Nahar K, Sultana N, Sharmin F. Socio-demographic Characteristics of Vesico-vaginal fistula (VVF) patients attended at a tertiary Care Hospital in Bangladesh. J Natl Inst Neurosci Bangladesh, 2020;6(2): 115-118

Copyright: (C2020. Akter et al. Published by Journal of National Institute of Neurosciences Bangladesh. This article is published under the Creative Commons CC BY-NC License (https://creativecommons.org/licenses/by-nc/4.0/). This license permits use, distribution and reproduction in any medium, provided the original work is properly cited, and is not used for commercial purposes.

\section{Introduction}

Vesico-vaginal fistula (VVF) is an abnormal communication between the urinary bladder and vagina resulting in an uncontrollable, involuntary leakage of urine in vagina ${ }^{1}$. This complication has been recognized since ancient times, being noted in the Egyptian mummy dating back to $2000 \mathrm{BC}^{2}$. It is still a common problem in the developing world, as 84 to $97 \%$ of cases occur in these countries ${ }^{3}$. True incidence of VVF is not known because many women do not seek medical advice for this complication and remain unreported. VVF may be congenital or acquired.

The etiology of acquired VVF may be iatrogenic, post radiation and related to malignancy. In developed countries, $90.0 \%$ of VVF are caused by gynaecological procedures $^{4-5}$. The iatrogenic fistulas caused by surgeries 
are seen most commonly in transabdominal and transvaginal hysterectomies and comprise $75 \%$ of fistulas ${ }^{6}$. Fistulas could also occur due to urological and gastrointestinal surgeries, illegal abortions, and in Lower Segment Caesarean Section (LSCS) $^{7}$ destructive operation like craniotomy. An overall incidence of $0.33 \%$ urinary tract injury has been reported in all pelvic surgeries. ${ }^{8}$. This constant dribbling of urine due to VVF has a profound effect not only on the physical health of the woman; it also causes immense psychosocial problems in her life".

Clinical presentations of VVF is straightforward. The woman gives history of continuous day and night leakage of urine per vagina and normal voiding does not occur. In case of ureterovaginal fistula, leakage of urine per vagina and normal act of voiding occur simultaneously. This difference is of great clinical importance for differentiation between vesicovaginal fistula and ureterovaginal fistula ${ }^{10}$. Uncontrolled leakage of urine into the vagina with unpleasant odour, excoriation of vulva and discomfort causes serious social, mental and physical problems for the women ${ }^{11}$. Robertson gave an emphatic account of the social and hygiene problems faced by the victims ${ }^{12}$. This present study was undertaken to see the socio-demographic characteristics of vesico-vaginal fistula (VVF) patients attended at a tertiary care hospital in Bangladesh.

\section{Methodology}

This present study was designed as descriptive cross-sectional study. This study was carried out from July 2013 to December 2013 for a period of 6 months. The study place was National Fistula Centre in the Department of Obstetrics \& Gynaecology at Dhaka Medical College Hospital (DMCH), Dhaka, Bangladesh. All patients who underwent surgical repair for iatrogenic VVF in National Fistula Centre of the department of Obstetrics and Gynaecology of Dhaka Medical College Hospital were included in this study. Patients who got themselves admitted to Obstetrics \& Gynaecology department of DMCH with the complaints of fistula. Women with stress incontinence and rectovaginal fistula, patients with severe co-morbidity or those patients who were unwilling to cooperate. Purposive non-probability sampling technique was used. A semi structured questionnaire was prepared after pre-testing containing patient profile. This was used for collection of information by interviewing and examining patients \& their reports. Data were collected for six months. An interview usually lasted for an hour. The entire selected patients were interviewed for detailed history. Thorough physical examination was done \& relevant lab investigations were arranged. Prior to the commencement of the study, the protocol was approved by the local research approval committee. Ethical clearance was obtained from ethical committee existent in DMCH. The aims and objectives of the study was explained to respondents and then informed \& verbal consent was taken from each subject. They were assured that all information and records would be kept confidential and be used for research purpose only. All the data were checked and edited after collection. Data were then entered into computer, with the help of SPSS for Windows (IBM SPSS Statistics for Windows, version 19.0, Armonk, NY, IBM Corp.) An analysis plan was developed keeping in view with the objectives of the study.

\section{Results}

A total number of 51 cases of VVF were recruited for this study who were fulfilled the inclusion and exclusion criteria. The leading age group was 41 to 50 years $(70.6 \%)$. The second leading age group was 51 to 60 years with more than $15.0 \%$ patients. About $12.0 \%$ patients were relatively younger $(\leq 40$ years). The age range was $38-70$ years. The mean age was $46.02( \pm$ SD $6.104)$ years (Table 1).

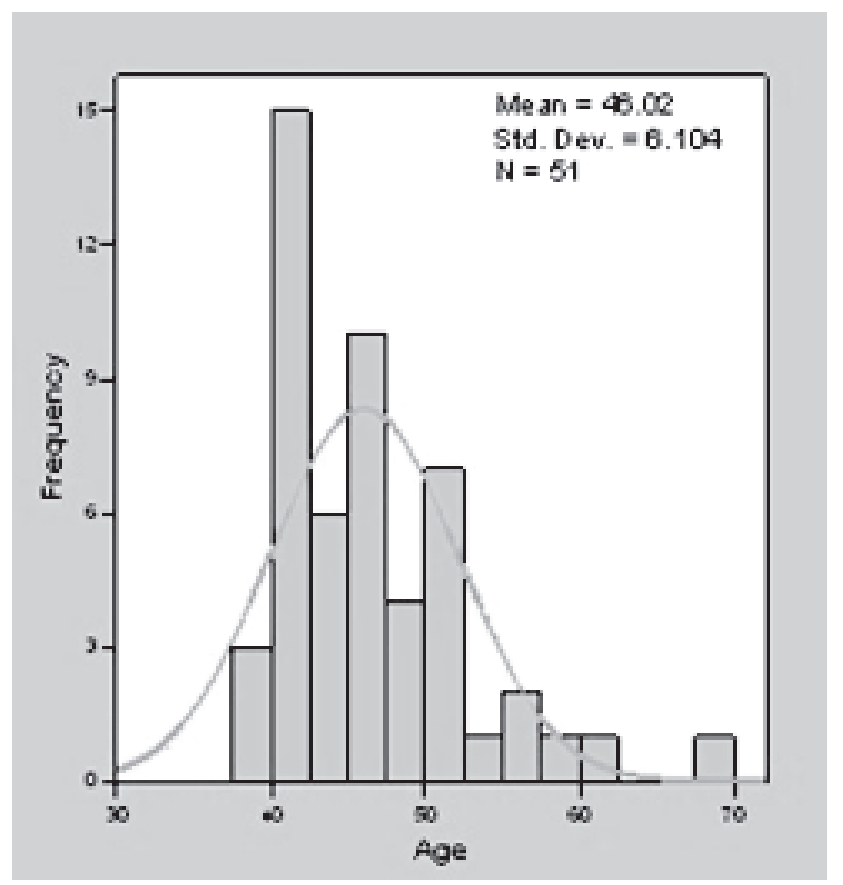

Figure I: Histogram showing Age Distribution of the Patients

The age range was 38 to 70 years. The mean age was $46.02( \pm$ SD 6.104$)$ years. The age distribution almost 
followed a normal curve (Figure I).

Table 1: Distribution of the patients by age group

\begin{tabular}{lcc}
\hline Age group & Frequency & Percent \\
\hline$\leq 40$ Years & 6 & 11.7 \\
41 to 50 Years & 36 & 70.6 \\
51 to 60 Years & 8 & 15.7 \\
$>60$ Years & 1 & 2.0 \\
Total & $\mathbf{5 1}$ & $\mathbf{1 0 0 . 0}$ \\
\hline
\end{tabular}

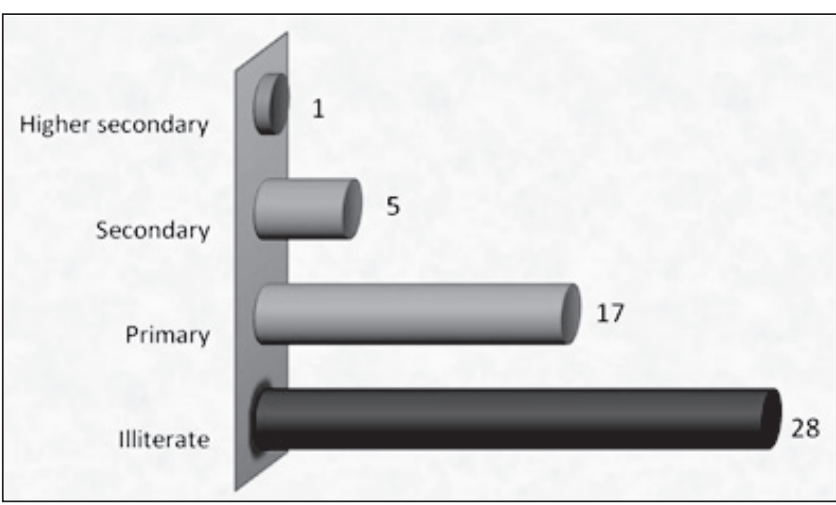

Figure II: Distribution of the patients by educational level

Most of the respondents were illiterate $(55.0 \%)$ and one-third patients had primary level education. The number of highly educated patients was scarce $(12.0 \%)$ (Figure II).

Table 2: Important continuous variables showing minimum value, maximum value, mean and $\mathrm{SD}$

\begin{tabular}{lcccc}
\hline Variables & Min. & Max. & Mean & SD \\
\hline Age at marriage & 10 & 30 & 15.80 & 4.737 \\
$\begin{array}{l}\text { Duration of } \\
\text { marriage (yrs) }\end{array}$ & 1 & 57 & 20.40 & 12.536 \\
$\begin{array}{l}\text { Interval between } \\
\text { menarche and }\end{array}$ & 1 & 27 & 4.72 & 4.824 \\
marriage(yrs) & & & & \\
Age at first delivery & 1 & 34 & 17.48 & 4.636 \\
Height (cm) & 131 & 155 & 146.37 & 5.593 \\
Weight (kg) & 30 & 78 & 48.37 & 10.074 \\
$\begin{array}{l}\text { Duration of urinary } \\
\text { incontinence (months) }\end{array}$ & 1 & 25 & 4.94 & 4.459 \\
\hline
\end{tabular}

$\mathrm{SD}=$ Standard Deviation

It was evident that average age at marriage of the patients was $15.8( \pm 4.74)$ years. Some females were forced to accept marriage at the age of 10 years. The mean interval between initiation of menstruation and the marriage was only 4.72 years. Mothers were on an average 17.48 years old at the time of first delivery. The average duration of urinary incontinence was almost 5 years (Table 2).

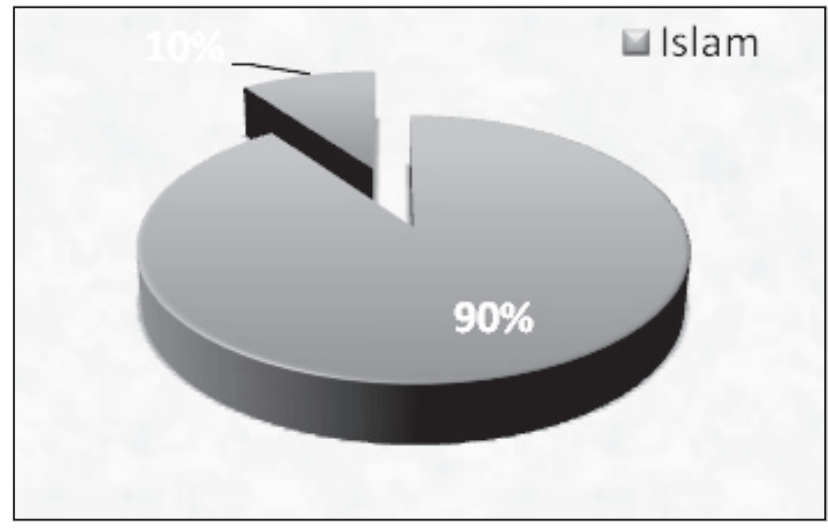

Figure III: Distribution of the patients by religion $(\mathrm{n}=51)$

Most of the respondents were Muslim (90\%) and the rest $10 \%$ patients were Hindu (Figure III).

\section{Discussion}

The VVF is the most common among the genitourinary fistulae and $90 \%$ of iatrogenic vesicovaginal fistulae are caused by gynecological procedures ${ }^{13}$. Hysterectomy, both by transabdominal and transvaginal approaches, is the most common procedure, comprising $75 \%$ of iatrogenic fistulae ${ }^{10}$. Globally, the overall incidence varies between 0.5 and $1.5 \%$, and bladder injuries are more common than ureteric ones ${ }^{14}$. In pelvic surgery the development risk of VVF is $0.22 \%$ in laparoscopic hysterectomy, $0.1 \%$ in abdominal hysterectomy and $0.02 \%$ in vaginal hysterectomy ${ }^{15}$. They emerge as a complication of gynecological surgery. The main symptom of VVF is leakage of urine from the vagina, apparent only when the bladder is full, or constantly in the presence of a large fistula. After gynecological surgery, leakage usually appears after removal of the urinary catheter ${ }^{16}$.

VVF can be treated with surgery or conservatively and the timing of repair remains controversial. According to the literature, it is apparent that there is no consensus as to the definition of late ( 2 to 4 months) and early (1 to 3 months) repair ${ }^{12}$. Conservative approaches such as catheter drainage, occlusion with fibrin, peeling of the tract epithelium with metal screw and steroid use have been reported in the literature for closure of small fistulas and outcome varies ${ }^{16}$.

In the current study a total of 51 cases were analyzed in the study. The mean age was $46.02( \pm \mathrm{SD} 6.104)$ years. Most of the respondents were illiterate $(55 \%)$ and one-third patients had primary level education. This socio-demographic scenario is almost identical to other study in developing countries ${ }^{7,13}$. One study in Turkey 
reported the mean patient age as $43( \pm \mathrm{SD} 3.86)$ years ${ }^{14}$. The alarming part is that majority of the cases occurred in middle age group and if not treated these women would have to spend a long part of their lives with this affliction, creating social and psychological problems in addition to medical issues.

Average age at marriage of the patients was only 15.8 $( \pm 4.74)$ years. In many cases, early marriage means long sexual life and giving birth to more children. It may contribute in the development uterine pathology. As a result, hysterectomy may be needed, eventually increasing the odds of having an iatrogenic VVF. Though, no direct evidence is yet available in this regard.

The average duration of urinary incontinence was almost 5 months. This makes sense as VVF developed as a consequence of a surgery both the parties remain conscious about the repair of the wound. One Pakistani study reported the average duration of urinary incontinence as 3 months $^{16}$. In $86 \%$ cases $(44 / 51)$ vaginal delivery was conducted. In $8 \%(4 / 41)$ cases assisted vaginal delivery was done. Only $6 \%(3 / 51)$ patients underwent caesarean section operation. The above findings are quite comparable with some international studies especially done in Pakistan ${ }^{10,13}$.

\section{Conclusion}

In conclusion middle age women are the most common age group who are suffering from VVF. Furthermore, majority women are illiterate women. However, young age mother are most commonly suffering from VVF. It is necessary to perform a large scale multicenter study.

\section{References}

1. Saba S, Kausar JS. Trans-vaginal sonographic evaluation of vesicovaginal fistula. J Pak Med Assoc 2005; 55:292-4

2. Spurlock J. Vesicovaginal fistula [Internet]. [updated 2009 Oct 1]. Available from: http://emedicine.medscape.com/article/ 267943-overview

3. Raut V, Bhattacharya M. Vesical fistulae: an experience from a developing country. J Postgrad Med 1993; 39:20-1

4. Smith GL, Williams G. Vesicovaginal fistulae. BJU Int 1999; 83:564-70

5. Tancer ML. Observations on prevention and management of vesicovaginal fistula after total hysterectomy. Surg Gynecol Obstet 1992; 175:501-6

6. Goodwin WE, Scordino PT. Vesicovaginal and uterovaginal fistulae: a summary of 25 years experience. J Urol 1980; 123-367

7. Puri M, Goyal U, Jain S, Pasrija S. A rare case of vesicovaginal fistula following illegal abortion. Indian J Med Sci 2005; 59:30-1 8. Bai SW, Huh EH, Jung da J, Park JH, Rha KH, Kim SK, et al. Urinary tract injuries during pelvic surgery: incidence rates and predisposing factors. Int Urogynecol J Pelvic Floor Dysfunct 2006; 17:360-4

9. Cook RJ, Dickens BM, Syed S. Obstetric fistula: the challenge to human rights. Int J Gynaecol Obstet 2004; 87:72-7

10. Shaikh AR, Shaikh S, Shaikh SN, Shaikh AH, Memon AA, Shaikh NA, Shaikh AF. Repair of vesico-vaginal fistula (Abdominal versus vaginal route). Professional Med J 2011; 18: 354-360

11. Rashid Y, Majeed T, Naeem M, et al. Iatrogenic vesicovaginal fistula JCPS 2010; 20: 436-438

12. Shafqat T, Faiz NR, Haleemi M. Profile and repair success of vesicovaginal fistula repair NWFP. JPMI 2009; 23:99-101

13. Sadiq G, Sadiq M, Sultana N. Obstetric trauma is the commonest cause of urogenital fistulae Rawal Med J 2008; 33: 197-200

14. Kostakopoulos A, Deliveliotis CH, Louras G, Giftopoulos A. Early repair of injury to the ureter or bladder after hysterectomy. Int Urol Nephrol. 1998; 30(4): 445-50

15. Walsh K, Stone AR. How is the lower urinary tract affected by gynecological surgery? BJU Int. 2004; 94: 272-75

16. Sachdev PS. Surgical repair of vesicovaginal fistula. J Coll Physicians Surg Pak 2002; 12:223-6 